\title{
A case of nasal cerebral heterotopia
}

\author{
Biplab Maji ${ }^{1}$, Dipankar Das ${ }^{2}$, Apurba Ghosh ${ }^{3}$
}

Sri Lanka Journal of Child Health, 2014; 43(2): 112-113

(Key words: Nasal cerebral heterotopia; nasal glioma)

\section{Case report}

An eighteen day old baby boy was brought by parents with the complaint of a fleshy mass coming out of left nostril since birth. There was a history of occasional nasal obstruction but without any history of epistaxis or other nasal discharge. The baby was the first in birth order, a product of a non consanguineous marriage and born at full term by a normal vaginal delivery. The family history was unremarkable.

On general physical examination, the baby was playful and haemodynamically stable. Examination of the nose revealed a lesion protruding through the left external nares like a polyp. The polyp was soft and pedunculated, non pulsatile, moving in and out with respiration and the skin over it had no special features. The pedicle was arising from the caudal part of the nasal septum. No change in size of the mass was observed during crying or on jugular vein compression (Furstenberg's test). The right nostril was patent. There were no other abnormalities.

Magnetic resonance imaging (MRI) revealed a well-defined soft tissue attenuation lesion, about $12 \mathrm{~mm} \times 9 \mathrm{~mm}$ in dimensions, at the caudal end of nasal septum in left side with a stalk. No bony defect or intracranial extension or other synchronous lesion was seen (Figures 1 and 2).

As the base of the pedicle was clearly visible, transnasal excision was done under general anaesthesia. There were no perioperative complications, and the patient was particularly observed for postoperative bleeding, cerebrospinal fluid leak, fever or other features of infection. Histopathological analysis of the specimen revealed non-malignant gliomatous cells with low proliferative activity. No meningeal or dural tissue was identified. The diagnosis of nasal glioma was hence established.

${ }^{1}$ Post Graduate Trainee, ${ }^{2}$ Associate Professor, Department of Radiology, ${ }^{3}$ Professor and Director, Institute of Child Health, 11 Biresh Guha Street, Kolkata 700017, India

(Received on 13 September 2013: Accepted after revision on 25 October 2013)

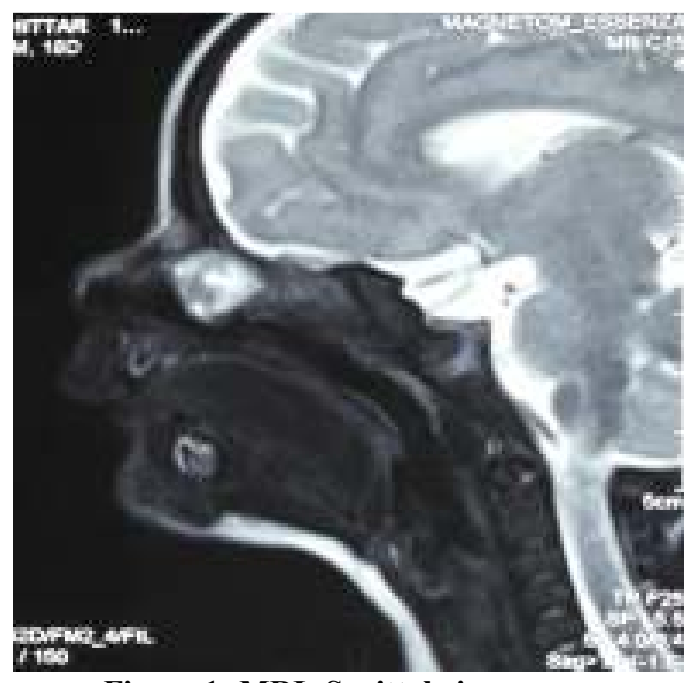

Figure 1: MRI- Sagittal view

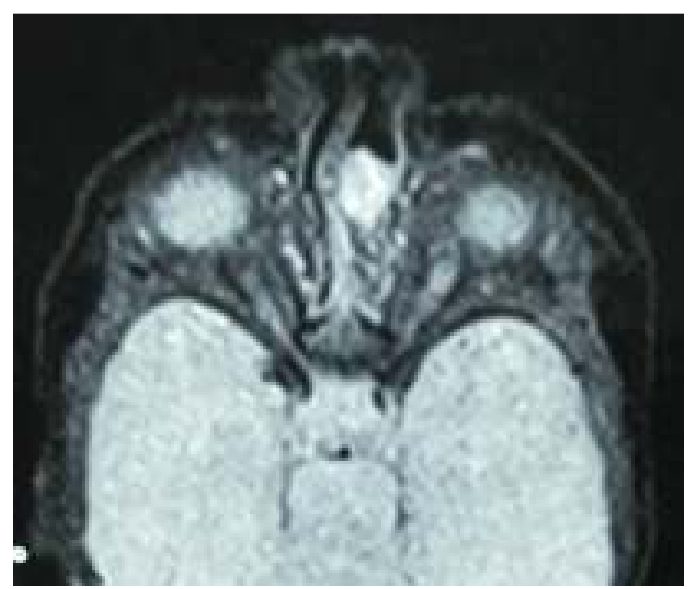

Figure 2: MRI-Coronal view

\section{Discussion}

The so-called nasal gliomas (nasal cerebral heterotopias) are rare, congenital, benign masses of neurogenic origin with intra or extra-nasal locations, or both. The reported incidence is 1 in every 20,000 to 40,000 births $^{1}$. The most common congenital nasal masses are nasal dermal sinus cysts, nasal encephaloceles, and nasal gliomas, all of which appear to share a similar embryogenic origin and occur when neuroectodermal and ectodermal tissues fail to separate during the development of the nose ${ }^{2}$. 
Some cases of nasal glioma associated with other malformations, such as agenesis of the corpus callosum and cleft palate, have been reported ${ }^{3}$. Histologically, these tumours are made up of astrocytic neuroglial cells interlaced with fibrous and vascular connective tissue that is covered with skin or nasal respiratory mucosa. The definitive treatment is complete surgical excision with removal of the entire mass to prevent recurrence. The preferred way of excision is via a frontal craniotomy approach for those patients whose gliomas have an intracranial connection, for those patients who have cerebrospinal fluid rhinorrhoea, and for those who have recurrent episodes of meningitis. Otherwise, a transfacial lateral rhinotomy is advised.

\section{References}

1. Paller AS, Pensler JM, Tomita T. Nasal midline masses in infants and children. Dermoids, encephaloceles, and gliomas. Archives of Dermatology 1991; 127:362-6. http://dx.doi.org/10.1001/archderm.127.3.362

2. Morgan DW, Evans JN. Developmental nasal anomalies Journal of Laryngology \& Otology 1990; 104:394-403.

http://dx.doi.org/10.1017/S0022215100158542

3. Harley EH. Paediatric congenital nasal masses. Ear Nose Throat Journal 1991; 70:28-32 